\title{
Exploring the Patient and Staff Experience With the Process of Primary Care
}

Elizabeth J. Brown, MD, MSHP ${ }^{1,2,3}$

Shreya Kangovi, MD, MSHP ${ }^{2,4,5}$

Cbristopher Sba, $M D^{6}$

Sarab Jobnson, $M D^{7}$

Casey Chanton, MSW

Tamala Carter, $\mathrm{CHW}^{5}$

David T. Grande, MD, MPA $A^{1,2,4}$

'The Robert Wood Johnson Foundation Clinical Scholars Program, Perelman School of Medicine of the University of Pennsylvania, Philadelphia, Pennsylvania

${ }^{2}$ The Leonard Davis Institute of Health Economics, University of Pennsylvania, Philadelphia, Pennsylvania

${ }^{3}$ The Department of Family and Community Medicine, Perelman School of Medicine of the University of Pennsylvania, Philadelphia, Pennsylvania

${ }^{4}$ The Division of General Internal Medicine, Perelman School of Medicine of the University of Pennsylvania, Philadelphia, Pennsylvania

${ }^{5}$ Penn Center for Community Health Workers, Philadelphia, Pennsylvania

${ }^{6}$ Department of Medicine, University of San Francisco, San Francisco, California

${ }^{7}$ Department of Internal Medicine, Johns Hopkins Hospital, Baltimore, Maryland

Conflicts of interest: authors report none.

\section{CORRESPONDING AUTHOR}

Elizabeth Brown, MD

13th Floor, Blockley Hall

Perelman School of Medicine

The University of Pennsylvania

423 Guardian Dr

Philadelphia, PA 19104

elizbro@upenn.edu

\begin{abstract}
PURPOSE Previous studies suggest that the highest-risk patients value accessible, coordinated primary care that they perceive to be of high technical quality. We have limited understanding, however, of how low-income, chronically ill patients and the staff who care for them experience each individual step in the primary care process.
\end{abstract}

METHODS We conducted qualitative interviews with uninsured or Medicaid patients with chronic illnesses, as well as with primary care staff. We interviewed 21 patients and 30 staff members with a variety of job titles from 3 primary care practices ( 1 federally qualified health center and 2 academically affiliated clinics).

RESULTS The interviews revealed 3 major issues that were present at all stages of a primary care episode: (1) information flow throughout an episode of care is a frequent challenge, despite systems that are intended to improve communication; (2) misaligned goals and expectations among patients, clinicians, and staff members are often an impediment to providing and obtaining care; and (3) personal relationships are highly valued by both patients and staff.

CONCLUSIONS Vulnerable populations and the primary care staff who work with them perceive some of the same challenges throughout the primary care process. Improving information flow, aligning goals and expectations, and developing personal relationships may improve the experience of both patients and staff.

Ann Fam Med 2015;13:347-353. doi: 10.1370/afm.1808.

\section{INTRODUCTION}

$\mathrm{H}$ igh-quality primary care is important for prevention and treatment of chronic diseases such as diabetes and hypertension, ${ }^{1}$ which disproportionately affect minorities and those of low socioeconomic status. ${ }^{2}$ Inadequate access to high-quality, patient-centered care $^{3}$ can have detrimental effects including poor outcomes, ${ }^{4}$ use of emergency services for nonurgent conditions, ${ }^{5,6}$ or forgoing care altogether., Patient experience, the measure of patient-centeredness, has become increasingly important in assessments of primary care quality. ${ }^{9}$

Patient experience surveys, however, have been used primarily with Medicare and privately insured populations, leaving the voices of patients in the lowest socioeconomic status underrepresented. ${ }^{10}$ Qualitative studies suggest that vulnerable patients place a high value on access to care, care coordination, and continuity, ${ }_{1}^{11,12}$ but may perceive primary care to be less accessible and of lower technical quality than hospital care. ${ }^{6}$

Patient experience is rarely compared with clinician experience, despite the fact that job satisfaction of both primary care clinicians and support staff has been correlated with patient satisfaction. ${ }^{13}$ Studies directly comparing patient and physician experience of insomnia and depression treatment in primary care have shown that disease understanding and expectations for treatment can affect the experience for both parties..$^{14,15}$ A qualitative study of patients, physicians, nurses, and administrative staff showed widespread agreement that communication and tailored "whole-person" care was essential to patient-centered care, 
and that vulnerable patients place a particularly high value on personal care. ${ }^{16}$ These studies assessed general perceptions and preferences, rather than experience with discrete care processes.

The goal of this study was to assess experiences at each step of the primary care process for low-income, chronically ill patients, who are at particularly high risk for poor outcomes, and the primary care clinicians and support staff who care for them. Using qualitative methods, participants guided the interviewer through everything that happened in an episode of care, from making an appointment, to navigating the office visit, to obtaining follow-up care. We uncovered areas of agreement and tension between the needs and preferences of high-risk patients and staff in the primary care setting.

\section{METHODS}

We conducted open-ended, semistructured interviews with clinic staff and high-risk patients from 2 academic primary care clinics and 1 federally qualified health center in Philadelphia between August 2012 and March 2013. All 3 clinics serve a high percentage of high-risk patients from a similar geographic area. The institutional review board of the University of Pennsylvania approved the study design and methods.

\section{Participants}

All staff members at each site were eligible and informed of the study by e-mail. We recruited staff participants via snowball sampling techniques ${ }^{17}$ beginning with 4 key informant interviews. At the end of each interview, we asked respondents to suggest others with a range of job titles in order to capture the viewpoints of multiple types of staff members. Given our expectations of the number of interviews required to reach thematic saturation, our goal was at least 20 staff interviews. ${ }^{18}$ Of the 36 staff members we invited to participate, 30 participated. The reasons for nonparticipation were not interested (4 members, $67 \%$ ), too busy ( 1 member, $17 \%)$, and unable to schedule a convenient time (1 member, 17\%).

A community health worker recruited patient participants either by telephone in advance of a scheduled appointment or in person in the clinic waiting room. We used the following inclusion criteria: (1) presence of 2 or more of the diagnoses of diabetes, asthma, chronic obstructive pulmonary disease, hypertension, hyperlipidemia, and obesity; $(2)$ uninsured, insured by Medicaid, or dually eligible for both Medicare and Medicaid; and (3) residence in a Zip code region where more than $30 \%$ of residents live below the federal poverty level. Insurance status ${ }^{19-21}$ and area-level poverty rates ${ }^{22-24}$ have been validated in several studies as markers of individual income. We excluded patients not seen in the past year, and those who lacked both capacity and a caregiver who could be interviewed on their behalf. As with staff participants, our goal was to complete at least 20 interviews. Of the 42 patients we approached, 21 completed an interview. The reasons for nonparticipation were too busy (12 patients, 57\%), feeling too unwell (6 patients, 27\%), unable to schedule a convenient time ( 2 patients, $9 \%$ ), and lack of capacity and caregiver proxy (1 patient, 5\%). We discontinued recruitment because we reached thematic saturation.

\section{Data Collection}

We developed semistructured, open-ended interview guides that asked participants to speak freely and in their own words about each step of the primary care process (Supplemental Appendix, available at http:// www.annfammed.org/content/13/4/347/suppl/DC1). The community health worker, who is trained in qualitative interviewing, performed all of the patient interviews in a private room on the same day as the office visit. After obtaining written consent, she asked patient respondents to describe the current episode of care, starting from the time when they developed a new problem by prompting, "What happened next?" to elicit each respondents' interpretations of the steps in the process.

Two trained research assistants conducted all of the staff interviews in person in a private room at the clinic. After obtaining written consent, the interviewers asked clinic staff respondents to describe what happened yesterday to get an overview of a typical work day. Interviewers then asked them to describe a primary care episode in the same way the patients did, starting from the time a patient called to make an appointment, prompting with, "What happened next?"

Interviewers asked participants to describe exactly what happened at each step, what could go wrong, and how it would work in an ideal world. All interviewers had a general framework for the primary care process and prompted interviewees to go back if they did not spontaneously address a step. All interviews were audio-recorded and transcribed.

\section{Data Analysis}

We used a modified grounded-theory approach, performing data collection and analysis concurrently. Using QSR NVivo 10.0 (QSR International), 2 trained research assistants coded the data beginning with an a priori set of codes based on the study questions. Using an iterative process of regular discussion, the study team modified the coding schema and interview guide to fully explore and reflect the findings that emerged through the experience of interviews and reading of 
the transcripts. ${ }^{25}$ When modifying the coding schema we used the constant comparison method, whereby coders compared each application of a code with all previous statements coded in that same category. ${ }^{26}$ Where interrater reliability for any individual node was less than $70 \%$, the team discussed all instances where that code was used to resolve discrepancies. Analysis confirmed that we reached thematic saturation with both patient and staff interviews.

\section{RESULTS}

Characteristics of the 51 study participants are given in Table 1. Practice staff had a mean age of 46 years; most (97\%) were female and about half (47\%) were black. They had diverse job titles. Patients had a mean age of 50 years; roughly half $(57 \%)$ were female and most (95\%) were black. On average, they had made more than 5 visits to an emergency department in the past 6 months.

Both practice staff and low-income, chronically ill patients identified 2 key challenges that affected multiple steps and frequently got in the way of an effective primary care visit: transferring information and aligning goals. Participants also brought up personal relationships as an important, usually positive element throughout the visit. Table 2 highlights examples of these 3 issues at each stage in the primary care episode.

\section{Information Flow}

Both patients and staff identified potential pitfalls at information handoffs throughout the primary care episode. Staff frequently identified the information transfer itself as the problem; patients were more likely to note the consequences, such as increased wait times or frustration with needing to repeat information.

When calling the clinic, many patients said that they liked having a person rather than an electronic system answer the telephone. When the person was provided in the form of a call center, however, some felt it added extra opportunity for the quality of information to degrade or to be lost completely. Staff seemed to reinforce this concern. Many patients said that when they left a message for their physician, the calls were frequently not returned or the important information in the message was lost. One patient said, "I don't think they are good at giving messages" and related a story about her medication refill being held up because the special instructions on her request were never communicated to the physician (Patient 1).

Another key handoff occurs while patients are put into examination rooms, as information needs to be transferred from patient to medical assistant (MA), and later to physician. Many staff members mentioned challenges here, but few patients did. During the "rooming" process, MAs complete required screenings, such as for falls or depression. When MAs identify concerns, there is not always a clear way to alert the physician. As one physician explained, "There may be a positive response meaning [the patient] fall[s] at home... but there may not be an easy way of alerting the physician to that" (Physician 1, Practice A). Staff indicated that the sheer volume of information in the electronic health record can obscure some of the important details.

After the visit, patients may be sent to other areas of the clinic for laboratory tests or additional services. Almost all staff members recognized that patients might leave without getting these services or follow-up appointments. The most commonly cited

\begin{tabular}{|c|c|}
\hline Characteristic & Value \\
\hline \multicolumn{2}{|l|}{ Practice staff $(n=30)$} \\
\hline Female, No. (\%) & $29(97)$ \\
\hline \multicolumn{2}{|l|}{ Race, No. (\%) } \\
\hline Black & $14(47)$ \\
\hline White & $11(37)$ \\
\hline Asian & $2(7)$ \\
\hline Other & $3(10)$ \\
\hline Age, mean (SD), y & $46(11.1)$ \\
\hline \multicolumn{2}{|l|}{ Practice site, No. (\%) } \\
\hline Federally qualified health center & $11(37)$ \\
\hline Academic practice & $19(63)$ \\
\hline \multicolumn{2}{|l|}{ Job title, No. (\%) } \\
\hline Administrator/Practice manager & $4(13)$ \\
\hline Call Center/Front desk/Scheduler & $7(23)$ \\
\hline Medical assistant & $2(7)$ \\
\hline Physician & $3(10)$ \\
\hline Nurse & $7(23)$ \\
\hline $\begin{array}{l}\text { Other (psychologist, nutritionist, case } \\
\text { manager, social worker, pharmacist) }\end{array}$ & $6(20)$ \\
\hline \multicolumn{2}{|l|}{ Patients $(n=21)$} \\
\hline Female, No. (\%) & $12(57)$ \\
\hline Black race, No. (\%) & $20(95)$ \\
\hline Age, mean (SD), y & $50(10.0)$ \\
\hline $\begin{array}{l}\text { Emergency department visits in } 6 \text { months } \\
\text { prior, mean (range), No. }\end{array}$ & $5.4(0-20)$ \\
\hline \multicolumn{2}{|l|}{ Insurance type, No. (\%) } \\
\hline Medicaid & $9(43)$ \\
\hline Uninsured & $8(38)$ \\
\hline Dually eligible (Medicare/Medicaid) & $3(14)$ \\
\hline \multicolumn{2}{|l|}{ Diagnoses, No. (\%) } \\
\hline Hypertension & $13(65)$ \\
\hline Hyperlipidemia & $10(50)$ \\
\hline Diabetes & $9(40)$ \\
\hline Mental illness/Addiction & $8(40)$ \\
\hline Obesity & $8(40)$ \\
\hline Congestive heart failure & $6(29)$ \\
\hline Asthma/chronic obstructive pulmonary disease & $5(20)$ \\
\hline
\end{tabular}


Table 2. Examples of Key Findings by Step in the Primary Care Process

\begin{tabular}{|c|c|c|c|c|c|}
\hline \multirow{2}{*}{$\begin{array}{l}\text { Key } \\
\text { Finding }\end{array}$} & \multirow{2}{*}{$\begin{array}{l}\text { Previsit } \\
\text { Scheduling } \\
\text { Appointments }\end{array}$} & \multicolumn{3}{|l|}{ Visit } & \multirow{2}{*}{$\begin{array}{l}\text { Postvisit } \\
\text { Laboratory } \\
\text { and Imaging }\end{array}$} \\
\hline & & Check-in & Rooming & Clinician Visit & \\
\hline $\begin{array}{l}\text { Information } \\
\text { flow }\end{array}$ & $\begin{array}{l}\text { Reason for visit not always } \\
\text { clearly communicated } \\
\text { or understood, leading } \\
\text { to patients getting visit } \\
\text { scheduled for some- } \\
\text { thing that could have } \\
\text { been dealt with over the } \\
\text { telephone }\end{array}$ & $\begin{array}{l}\text { Changes to addresses } \\
\text { or insurance infor- } \\
\text { mation need to be } \\
\text { updated in mul- } \\
\text { tiple places }\end{array}$ & $\begin{array}{l}\text { Problems identified } \\
\text { by MAs during } \\
\text { screening not } \\
\text { always seen by } \\
\text { physician }\end{array}$ & $\begin{array}{l}\text { Medication lists fre- } \\
\text { quently not recon- } \\
\text { ciled appropriately } \\
\text { because patients } \\
\text { assume the com- } \\
\text { puter is correct }\end{array}$ & $\begin{array}{l}\text { Laboratory orders not } \\
\text { entered correctly or } \\
\text { did not print, which } \\
\text { causes confusion or } \\
\text { errors when patient } \\
\text { goes to laboratory }\end{array}$ \\
\hline $\begin{array}{l}\text { Alignment of } \\
\text { goals and } \\
\text { expectations }\end{array}$ & $\begin{array}{l}\text { Open-access schedul- } \\
\text { ing can conflict with } \\
\text { patient's need to be } \\
\text { able to plan ahead }\end{array}$ & $\begin{array}{l}\text { Patients frustrated } \\
\text { with not being seen } \\
\text { when late, even } \\
\text { when public trans- } \\
\text { portation issues } \\
\text { were the cause }\end{array}$ & $\begin{array}{l}\text { MAs caught between } \\
\text { need to keep } \\
\text { flow moving and } \\
\text { increasing num- } \\
\text { ber of screening } \\
\text { questions they are } \\
\text { expected to ask }\end{array}$ & $\begin{array}{l}\text { Patients have mul- } \\
\text { tiple concerns, and } \\
\text { clinicians may be } \\
\text { willing to address } \\
\text { only } 1 \text { or } 2 \text { or pri- } \\
\text { oritize chronic dis- } \\
\text { ease management }\end{array}$ & $\begin{array}{l}\text { Prior authorization } \\
\text { requirements of } \\
\text { insurance companies } \\
\text { conflict with patient } \\
\text { and clinician desire } \\
\text { for rapid access to } \\
\text { needed tests }\end{array}$ \\
\hline $\begin{array}{l}\text { Personal } \\
\text { relationships }\end{array}$ & $\begin{array}{l}\text { Knowing which patients } \\
\text { will have trouble sched- } \\
\text { uling follow-up can help } \\
\text { care coordinators decide } \\
\text { whom to schedule in } \\
\text { advance }\end{array}$ & $\begin{array}{l}\text { Patients feel comfort- } \\
\text { able with front } \\
\text { desk staff whom } \\
\text { they have known } \\
\text { for many years }\end{array}$ & $\begin{array}{l}\text { Patients more likely } \\
\text { to discuss true rea- } \\
\text { son for visit with } \\
\text { staff they know } \\
\text { well }\end{array}$ & $\begin{array}{l}\text { Trust between } \\
\text { patients and clini- } \\
\text { cians develops } \\
\text { with time }\end{array}$ & $\begin{array}{l}\text { Walking patients to } \\
\text { laboratory prevents } \\
\text { them from leaving } \\
\text { before having tests } \\
\text { completed }\end{array}$ \\
\hline
\end{tabular}

reasons were lack of communication to the patient about the next steps, patient frustration about an additional wait time, and technology that fails to alert the next person in line about the plan. Technology in particular was a frustration: "Sometimes the doctors forgot that they ordered an x-ray and it didn't print out, or they did really know that they ordered it and it just didn't print out. So we have to go in the system and reprint lab orders, different testing..." (Front desk staff 1 , Practice A). Many staff members pointed to a disconnect between the potential of technology and the way it works in reality because of system malfunction, such as orders not printing correctly or user error, such as not manually updating patient status as they move through the episode.

According to several patients, they expect the computer to be an important source of information transfer at all stages. Some expressed relief that they did not need to remember all of their medications because those are recorded in the electronic health record. In contrast, several staff members noted that the electronic medication lists are frequently incorrect, at times because it is unclear whose responsibility it is to update them, or because patients do not know that what they are actually taking differs from the electronic list. Some patients expressed frustration at having to go through their health history: "You should already know what's going on, you've got a big screen in front of you, you have my whole life history since I was 4 in there..." (Patient 2). Staff indicated that although essential information is usually present in the record, it is not always organized in a way that is easily accessible in the moment.

\section{Alignment of Goals and Expectations}

Each person involved in the primary care process has particular goals and expectations about how they should be met. Misaligned goals or lack of awareness of the interests of other parties could create problems throughout the process. This was particularly evident, however, at 2 steps: during rooming and when the physician was with the patient.

For many patients, expectations of having their immediate concern fully resolved conflicts with clinicians' desire to maximize opportunities to address chronic health conditions. This conflict was common with pain concerns: "We barely discussed my back... He wanted to talk about blood pressure medication and then my pharmacy that I go to" (Patient 3). Staff almost universally said that in an ideal world, patients would clearly state the 1 or 2 reasons that they came to the clinic at the very beginning of the visit, but patients indicated that there are often multiple reasons for seeing their clinician. One clinician summed it up this way: "I think sometimes the patients may not feel like their concerns are addressed, and I think sometimes a provider may feel like the patient has too many things that they want to have addressed in 1 visit. So, that can lead to conflict... the time constraints on both ends" (Physician 2, Practice B).

Similarly, the goals of different types of staff members are not always aligned, at times because of 
differing expectations placed on them by the health care system. For example, MAs are often pulled in different directions, expected to serve both patients and clinicians. While MAs are rooming patients, checking vital signs, and completing the required screenings mentioned above, clinicians may be waiting for them to chaperone a breast or pelvic examination. Similar challenges come up at the front desk, where staff need to balance patients waiting to check in with the expectations that they will be scheduling follow-up and specialty appointments.

\section{Personal Relationships}

Despite the many challenges identified by both patients and clinic staff, a personalized touch stood out as a positive in both patient and staff comments. Patients said they are more satisfied and more likely to be open with a physician who knows them well because "she's on top of everything" (Patient 4) and "I like that she remembers things" (Patient 5). Knowing the patient may make staff members' jobs easier, too. For example, it may help case managers and front desk staff know who needs extra assistance with planning follow-up: "Just from seeing the patients daily and getting to know my patients, I know who needs what" (Front desk staff 1, Practice A).

The length of the relationship, however, is not the only thing that facilitates a positive relationship or helps develop trust. Job title may play a role; some staff noted that patients are more likely to share sensitive information with the physician only: "So you may have a patient come in [and say]...it's only between me and my doctor, and I don't want you to know why I came in here" (Licensed Practical Nurse 1, Practice A). Some patients feel more comfortable, however, with nonphysician staff. One staff member noted that patients may feel intimidated to ask questions of their physician: "They say, well, doctor said for me to do such and such. I didn't understand what he said. So can you find out for me? Because a lot of times they will tell their MAs things that they won't tell their doctors... because, for whatever reason, they may think that they are not on the same terms, or they don't understand and they don't want to let the doctor know they don't understand" (Registered Nurse 2, Practice C). Gender was also mentioned as a factor affecting with whom patients feel comfortable sharing certain information.

Some of the solutions offered by both patients and staff related to providing more personalized attention. For example, multiple staff members suggested that an after-visit escort through checkout to provide continuity and individualized navigation would make it less likely patients leave the clinic before completing all of their follow-up steps.

\section{DISCUSSION}

We undertook this study to understand the process of accessing and using primary care as voiced by low-income, chronically ill patients and clinic staff who care for them. The interviews revealed 3 major findings that were present at all stages of a primary care episode: (1) information flow is a frequent challenge, despite systems that are intended to improve communication, (2) misaligned goals and expectations among patients, clinicians, and staff members are often an impediment to providing and obtaining care; and (3) personal relationships are highly valued by both patients and staff. These 3 findings have different implications for future initiatives. The first finding suggests a need for experimentation with discrete steps in primary care that involve information transfer and potential improvement on processes that already exist. The latter 2, however, provide an overall context that should be considered for future primary care improvement efforts.

The patient-centered medical home (PCMH) movement has accelerated changes in primary care over the last several years. Although the clinics we studied are implementing this model, our study was not designed to assess the impact of $\mathrm{PCMH}$ on the patient experience. The findings that arose, however, relate to some of the same issues that it is designed to address. ${ }^{27}$ Care coordination is one of the core PCMH principles, with an emphasis on the use of information technology. The staff and patients in our study suggested that information flow even within the clinic encounter was an issue, despite the use of information technology. Identification of areas of information loss may provide definitive points for potential intervention in the clinic.

Assessing patient goals and expectations is implicit in the PCMH principles, but our results suggest that explicit attention to the alignment across the care episode might be useful. Interventions to train physicians in patient-centered care techniques have been shown to be effective in skill development. ${ }^{28,29}$ Eliciting patient goals effectively may help clinicians address misalignment. Whether use of these skills persists over time, however, and the effect of similar training for other members of the health care staff is unknown.

Our results highlight the importance of personal relationships, which the PCMH fundamental principles address by calling for each patient to have a personal physician. Previous qualitative work suggests that continuity of care can contribute to the development of a trusting physician-patient relationship..$^{30,31}$ The respondents in our study, however, mentioned ways in which other relationships are important throughout a primary care episode. Tarrant et $\mathrm{al}^{16}$ also found that interactions 
with nonphysician team members and brief interactions without a longitudinal aspect could still effectively create a sense of personalized care in some instances. As team roles are redefined in new primary care delivery models, we should continue to evaluate the importance of different types of relationships. ${ }^{32}$

Our study has several important limitations. Because the interview guide used the prompt "then what happened?" to move through the primary care episode, we may have missed important nonprocess elements. For example, physical structure and clinic design elements that people may not consciously notice can nonetheless affect outcomes. ${ }^{33}$ We interviewed only patients who were able to schedule and attend a clinic visit; people unable to do so, who may be even more vulnerable, were not represented. Also, the setting and participant demographics limit the generalizability of our findings. Our study was conducted in urban academic and federally qualified health center settings with a primarily black patient population. Nearly all of our staff participants were women. Lack of gender diversity in our sample may have led to reaching thematic saturation prematurely.

To our knowledge, this is the first qualitative study that concurrently assesses the experience of vulnerable patients and staff with each step of the primary care process. As patient-centeredness in primary care continues to gain attention, individual clinics and primary care system leadership need to make decisions about how to adapt initiatives to their local setting. Taking all participants' perspectives into account, especially as they relate to information flow, goals and expectations, and personal relationships, may be important when considering how to improve the care of low-income, chronically ill patients.

To read or post commentaries in response to this article, see it online at http://www.annfammed.org/content/13/4/347.

Key words: patients; medical staff; patient-centered medical home; primary care; practice-based research; process of care; office visits; chronic illness; vulnerable populations; qualitative research

Submitted July 28, 2014; submitted, revised, March 16, 2015; accepted April 21, 2015.

Funding support: The study was funded by grants from the University of Pennsylvania Center for Therapeutic Effectiveness Research and the Leonard Davis Institute for Health Economics.

Supplementary materials: Available at http://www.AnnFamMed. org/content/13/4/347/suppl/DC1/

\section{References}

1. Starfield B, Shi L, Macinko J. Contribution of primary care to health systems and health. Milbank Q. 2005;83(3):457-502.
2. Beal AC, Doty MM, Hernandez SE, Shea KK, Davis K. Closing the Divide: How Medical Homes Promote Equity in Health Care. New York, NY: The Commonwealth Fund; 2007.

3. Institute of Medicine. Crossing the Quality Chasm: A New Health System for the 21st Century. Washington, DC: National Academies Press; 2001.

4. National Association of Community Health Centers and The Robert Graham Center. Access Denied: A Look at America's Medically Disenfranchised. Washington, DC: National Association of Community Health Centers and The Robert Graham Center; 2007.

5. Rust G, Ye J, Baltrus P, Daniels E, Adesunloye B, Fryer GE. Practical barriers to timely primary care access: impact on adult use of emergency department services. Arch Intern Med. 2008;168(15): 1705-1710.

6. Kangovi S, Barg FK, Carter T, Long JA, Shannon R, Grande D. Understanding why patients of low socioeconomic status prefer hospitals over ambulatory care. Health Aff (Millwood). 2013;32(7):1196-1203.

7. Shi L, Stevens GD. Vulnerability and unmet health care needs: the influence of multiple risk factors. J Gen Intern Med. 2005;20(2): 148-154.

8. Ayanian JZ, Weissman JS, Schneider EC, Ginsburg JA, Zaslavsky AM. Unmet health needs of uninsured adults in the United States. JAMA. 2000;284(16):2061-2069.

9. Anhang Price R, Elliott MN, Zaslavsky AM, et al. Examining the role of patient experience surveys in measuring health care quality. Med Care Res Rev. 2014;71(5):522-554.

10. Browne K, Roseman D, Shaller D, Edgman-Levitan S. Analysis \& commentary. Measuring patient experience as a strategy for improving primary care. Health Aff (Millwood). 2010;29(5):921-925.

11. Kangovi S, Kellom K, Sha C, et al. Perceptions of high-risk patients and their providers on the patient-centered medical home. J Ambul Care Manage. 2015;38(2):134-143.

12. DeCamp LR, Kieffer E, Zickafoose JS, et al. The voices of limited English proficiency Latina mothers on pediatric primary care: lessons for the medical home. Matern Child Health J. 2013;17(1):95-109.

13. Szecsenyi J, Goetz K, Campbell S, Broge B, Reuschenbach B, Wensing $M$. Is the job satisfaction of primary care team members associated with patient satisfaction? BMJ Qual Saf. 2011;20(6):508-514.

14. Dyas JV, Apekey TA, Tilling M, Ørner R, Middleton H, Siriwardena AN. Patients' and clinicians' experiences of consultations in primary care for sleep problems and insomnia: a focus group study. $\mathrm{Br}$ J Gen Pract. 2010;60(574):e180-e200.

15. Keeley RD, West DR, Tutt B, Nutting PA. A qualitative comparison of primary care clinicians' and their patients' perspectives on achieving depression care: implications for improving outcomes. BMC Fam Pract. 2014;15:13.

16. Tarrant C, Windridge K, Boulton M, Baker R, Freeman G. How important is personal care in general practice? BMJ. 2003;326 (7402):1310.

17. Charmaz K. Premises, principles, and practices in qualitative research: revisiting the foundations. Qual Health Res. 2004;14(7):976-993.

18. Guest G, Bunce A, Johnson L. How many interviews are enough? An experiment with data saturation and variability. Field Methods. 2006;18(1):59-82.

19. Ayanian JZ, Kohler BA, Abe T, Epstein AM. The relation between health insurance coverage and clinical outcomes among women with breast cancer. N Engl J Med. 1993;329(5):326-331.

20. Foraker RE, Rose KM, Whitsel EA, Suchindran CM, Wood JL, Rosamond WD. Neighborhood socioeconomic status, Medicaid coverage and medical management of myocardial infarction: Atherosclerosis Risk in Communities (ARIC) community surveillance. BMC Public Health. 2010;10:632.

21. Harnick DJ, Cohen JL, Schechter CB, Fuster V, Smith DA. Effects of practice setting on quality of lipid-lowering management in patients with coronary artery disease. Am J Cardiol. 1998;81(12):1416-1420. 
22. Krieger N, Chen JT, Waterman PD, Rehkopf DH, Subramanian SV. Race/ethnicity, gender, and monitoring socioeconomic gradients in health: a comparison of area-based socioeconomic measures-the public health disparities geocoding project. Am J Public Health. 2003;93(10):1655-1671.

23. Krieger N, Chen JT, Waterman PD, Soobader MJ, Subramanian SV, Carson R. Geocoding and monitoring of US socioeconomic inequalities in mortality and cancer incidence: does the choice of areabased measure and geographic level matter? The Public Health Disparities Geocoding Project. Am J Epidemiol. 2002;156(5):471-482.

24. Krieger N, Waterman P, Chen JT, Soobader MJ, Subramanian SV, Carson R. Zip code caveat: bias due to spatiotemporal mismatches between zip codes and US census-defined geographic areas-the Public Health Disparities Geocoding Project. Am J Public Health. 2002;92(7):1100-1102.

25. Charmaz K. Grounded theory as an emergent method. In: HesseBiber SN, Leavy P, eds. Handbook of Emergent Methods. New York, NY: The Guilford Press; 2008:155-172.

26. Glaser BG. The constant comparative method of qualitative analysis. Social Problems. 1965;12(4):436-445.

27. American Academy of Family Physicians (AAFP). Joint Principles of the Patient-Centered Medical Home. http://www.aafp.org/dam/ AAFP/documents/practice_management/pcmh/initiatives/PCMHJoint.pdf. Published Feb 2007. Accessed Dec 2, 2014.
28. Brock DM, Mauksch LB, Witteborn S, Hummel J, Nagasawa P, Robins LS. Effectiveness of intensive physician training in upfront agenda setting. J Gen Intern Med. 2011;26(11):1317-1323.

29. Dwamena F, Holmes-Rovner M, Gaulden CM, et al. Interventions for providers to promote a patient-centred approach in clinical consultations. Cochrane Database Syst Rev. 2012;12:CD003267.

30. Haggerty JL, Roberge D, Freeman GK, Beaulieu C. Experienced continuity of care when patients see multiple clinicians: a qualitative metasummary. Ann Fam Med. 2013;11(3):262-271.

31. Tarrant C, Dixon-Woods M, Colman AM, Stokes T. Continuity and trust in primary care: a qualitative study informed by game theory. Ann Fam Med. 2010;8(5):440-446.

32. Carrier E, Gourevitch MN, Shah NR. Medical homes: challenges in translating theory into practice. Med Care. 2009;47(7):714-722.

33. Joseph A, Keller A, Gulwadi GB. Improving the Patient Experience: Best Practices for Safety-Net Clinic Redesign. Oakland, CA: The Center for Health Design; 2009.

\section{CHANGE-OF-ADDRESS FORM

Please complete this form and mail to the following address or fax to Annals Circulation at 913-906-6080:

Annals of Family Medicine, Circulation Department, 11400 Tomahawk Creek Pkwy, Leawood, KS 66211-2680

Check if member of sponsoring organization:

$$
\begin{array}{ll}
\square \text { AAFP } & \square \text { ABFM } \square \text { STFM } \square \text { ADFM } \\
\square \text { AFMRD } & \square \text { NAPCRG } \square \text { CFPC }
\end{array}
$$

ID number from label on your journal cover

OLD Information (Please print.)

\begin{tabular}{lc}
\hline Name \\
\hline Company (if applicable) \\
\hline Address (Street plus Apt or Ste) \\
\hline City \\
\hline Country \\
\hline Telephone \\
\hline E-Mail & Faxtal Code (9-digit ZIP for US) \\
\hline
\end{tabular}

NEW Information (Please print.)

\begin{tabular}{ll}
\hline Name \\
\hline Company (if applicable) \\
\hline Address (Street plus Apt or Ste) \\
\hline City & Postal Code (9-digit ZIP for US) \\
\hline Country & Fax \\
\hline Telephone & \\
\hline E-Mail &
\end{tabular}

